\title{
Pathological tumor volume predicts survival outcomes in oral squamous cell carcinoma
}

\author{
NOBUAKI MUKOYAMA ${ }^{1,2^{*}}$, HIDENORI SUZUKI ${ }^{2 *}$, NOBUHIRO HANAI $^{2}$, \\ MICHIHIKO SONE $^{1}$ and YASUHISA HASEGAWA ${ }^{2}$ \\ ${ }^{1}$ Department of Otorhinolaryngology, Nagoya University Graduate School of Medicine, Nagoya, Aichi 466-8560; \\ ${ }^{2}$ Department of Head and Neck Surgery, Aichi Cancer Center Hospital, Nagoya, Aichi 464-8681, Japan
}

Received December 22, 2017; Accepted May 24, 2018

DOI: $10.3892 / \mathrm{ol} .2018 .8951$

\begin{abstract}
The present study examined whether the pathological tumor volume (PTV) was correlated with the survival outcomes in patients with oral squamous cell carcinoma (SCC) and clinical lymph node metastasis. Forty-seven patients who underwent radical surgery without preoperative treatment were enrolled. The PTV of the primary tumor, which was surgically resected without preoperative treatment, was calculated based on the diameters in three dimensions. A survival analysis was performed using a Cox proportional hazards model. A PTV of $\geq 18 \mathrm{~cm}^{3}$ was significantly correlated with shorter overall survival $(\mathrm{P}<0.01)$ and local recurrence-free survival $(\mathrm{P}<0.01)$ in a univariate analysis. A multivariate analysis with adjustment for the pathological stage (stage I-II/III-IV), primary site (tongue/others) and positive surgical margin and/or extracapsular extension (absent/present) showed that a PTV of $\geq 18 \mathrm{~cm}^{3}$ was significantly correlated with shorter overall survival $(\mathrm{P}<0.01)$ and local recurrence-free survival $(\mathrm{P}<0.01)$. The present findings suggested that PTV in oral SCC provides a prognostic parameter that may predict shorter or longer overall and local recurrence-free survival.
\end{abstract}

\section{Introduction}

The tumor-node-metastasis (TNM) classification is a widely accepted system for estimating the prognosis in various types of cancer $(1,2)$. The TNM staging system in head and neck

Correspondence to: Dr Yasuhisa Hasegawa, Department of Head and Neck Surgery, Aichi Cancer Center Hospital, 1-1 Kanokoden, Chikusa-ku, Nagoya, Aichi 464-8681, Japan

E-mail: hasegawa@aichi-cc.jp

*Contributed equally

Abbreviations: PTV, pathological tumor volume; SCC, squamous cell carcinoma; TNM, tumor-node-metastasis

Key words: pathological tumor volume, oral squamous cell carcinoma, overall survival, local recurrence-free survival, prognosis squamous cell carcinoma (SCC), including oral SCC, is reported to be unable to predict the survival outcomes of patients at the same stage (2-4). Numerous studies have researched the prognostic parameters of oral SCC using various approaches, including clinical and pathological procedures (5-8). The pathological tumor volume (PTV) of the primary tumor is calculated after surgical resection by measuring its diameters in three dimensions (9-13). Recently, the PTV in tongue SCC, which is part of the oral cavity, was reported to be significantly correlated with the survival outcome (9). However, to the best of our knowledge, the association between the PTV and overall survival in patients with SCC of the entire oral cavity has not been investigated.

In the present study, we investigated the possible association between the PTV and overall survival in patients with both oral SCC and clinical lymph node metastasis.

\section{Materials and methods}

Patients and methods. From January 2008 to December 2013, 56 patients, who were newly diagnosed with oral cancer with clinical lymph node metastasis, underwent surgery without preoperative treatment at the Department of Head and Neck Surgery, Aichi Cancer Center Hospital. We excluded six patients with histological types other than SCC, one patient with carcinoma in situ of the primary site, one patient with synchronous colon cancer, and one patient in whom it was not possible to define a theoretically reconstructed normal mucosal line in the pathological examination. Thus, a total of 47 patients were enrolled in this study. The sites of the primary tumor were as follows: Tongue, $n=29$; lower gum, $n=6$; upper gum, $n=5$; floor of mouth, $n=3$; buccal mucosa, $n=2$; and hard palate, $n=2$. This study was approved by the institutional review board, and all patients provided their informed consent for all of the examinations and treatments. The clinical stage was determined by physical examinations and enhanced cervical computed tomography, ${ }^{18} \mathrm{~F}$-fluorodeoxyglucose-positron emission tomography with computed tomography or magnetic resonance imaging. The TNM classification system of the International Union Against Cancer (seventh edition) was used for the staging of the tumors (14). Surgically resected tissues were fixed with formalin and embedded in paraffin. Representative sections of the paraffin-embedded tissues were 
cut and stained with hematoxylin and eosin. The pathological examinations were performed by two experienced pathologists.

The measurement of the pathological parameters. The tumor size was defined as the greatest dimension of the primary tumor, as measured in the pathological examination. The tumor thickness, depth of invasion, and PTV were measured as described previously $(7,10)$. Both the tumor thickness and the depth of invasion were measured by microscopic examinations using an ocular micrometer with an accuracy of $0.1 \mathrm{~mm}$. The tumor thickness was assessed as the distance from the surface of the tumor to the site that showed the deepest invasion. The depth of invasion was measured as the distance from the theoretically reconstructed normal mucosal line to the site that showed the deepest invasion. The PTV was calculated using the following formula: PTV $=\pi / 6{ }^{*}\left(\mathrm{X}_{\mathrm{path}} \mathrm{X} \mathrm{Y}_{\mathrm{path}} \mathrm{X} \mathrm{Z}_{\text {path }}\right)$. Both $X_{\text {path }}$ and $Y_{\text {path }}$ were obtained from the pathological report, and $\mathrm{Z}_{\text {path }}$ was assessed by the tumor thickness. A representative image from the pathological examination is shown in Fig. 1.

Statistical analysis. All of the statistical analyses were performed using the JMP software program (version 11; SAS; Cary, NC, USA). The relationships between the PTV and the clinicopathological parameters (gender, age, tumor site, pathological $\mathrm{T}$ classification, pathological $\mathrm{N}$ classification, pathological stage, positive surgical margin, extracapsular extension, postoperative radiation, and positive surgical margin and/or extracapsular extension) were analyzed using a t-test, Mann-Whitney U test, or Kruskal-Wallis test, as appropriate. The relationships between the PTV and the pathological parameters (size, tumor thickness, and depth of invasion) were assessed by a simple regression analysis. The Kaplan-Meier method was used to estimate the survival time. We defined the survival time as the period from surgery to a target event or last contact. The target events included death (for overall survival), local recurrence (for local recurrence-free survival), regional recurrence (for regional recurrence-free survival), and distant metastasis (for distant metastasis-free survival) (15). Applying a modification of a previously described method $(15,16)$, various PTV cut-off values were tested using a Cox proportional hazards model of univariate overall survival. Since a PTV of $18 \mathrm{~cm}^{3}$ was found to significantly differentiate the shorter survival group from the longer survival group in the univariate analysis of overall survival, all of the patients were separated into two groups based on the PTV (PTV $<18 \mathrm{~cm}^{3}$ or PTV $\geq 18 \mathrm{~cm}^{3}$ ). The relationship between both the clinicopathological parameters and the pathological parameters in these two groups was compared using the chi-squared test and the Mann-Whitney U test. The two groups (PTV $<18 \mathrm{~cm}^{3}$ and $\mathrm{PTV} \geq 18 \mathrm{~cm}^{3}$ ) were compared by univariate analyses of local recurrence-free survival, regional recurrence-free survival, and distant metastasis-free survival. We performed multivariate analyses (overall survival and local recurrence-free survival) with adjustments for the primary site (tongue/others), pathological stage (stage I-II/stage III-IV), and positive surgical margin and/or extracapsular extension (absent/present) using a Cox proportional hazards model. P-values of $<0.05$ were considered to indicate statistical significance.

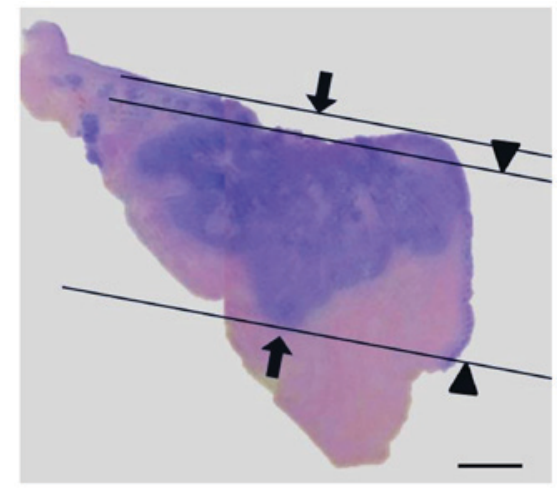

Figure 1. Tumor thickness between arrowheads and depth of invasion between arrows were measured during a microscopic examination of hematoxylin and eosin stained sections using an ocular micrometer. Scale bar=5 $\mathrm{mm}$. The tumor thickness was assessed as the distance from the surface of the tumor to the deepest invasion. The depth of invasion was measured as the distance from the theoretically reconstructed normal mucosal line to the deepest invasion.

\section{Results}

The PTV and the clinicopathological parameters. The mean \pm standard deviation PTV of the whole study population was $10.30 \pm 12.03 \mathrm{~cm}^{3}$. The associations between the PTV and the clinicopathological parameters are shown in Table I. The PTV was significantly correlated with the pathological T classification $(\mathrm{P}<0.01)$, pathological stage $(\mathrm{P}<0.02)$, and a positive surgical margin $(\mathrm{P}<0.03)$.

The PTV and the pathological parameters. A simple regression analysis was performed to analyze the associations between the PTV and the pathological parameters (Fig. 2). The PTV was significantly correlated with the size $(r=0.82$, $\mathrm{P}<0.01)$, tumor thickness $(\mathrm{r}=0.87, \mathrm{P}<0.01)$, and depth of invasion $(r=0.62, \mathrm{P}<0.01)$.

The clinical course. The median follow-up period was 23 months (range 3-77 months). Eighteen of the overall patients (38.3\%) died before the end of the study. Nine $(19.1 \%$, vs. all), 10 (21.3\%, vs. all), and 10 (21.3\%, vs. all) patients exhibited local recurrence, regional recurrence, and distant metastasis, respectively. At the end of the study, the rates of overall survival, local recurrence-free survival, regional recurrence-free survival, and distant metastasis-free survival in the whole study population were $58.5,78.2,37.8$, and $74.4 \%$, respectively.

The univariate survival analysis. Various cut-off PTV values were tested using a Cox proportional hazard model in the univariate analysis of overall survival, and a PTV of $18 \mathrm{~cm}^{3}$ was found to have the lowest P-value (Fig. 3). The univariate analysis of overall survival revealed that a PTV of $18 \mathrm{~cm}^{3}$ significantly differentiated the shorter overall survival group (PTV $\geq 18 \mathrm{~cm}^{3}$ ) from the longer overall survival group (PTV $<18 \mathrm{~cm}^{3}$ ). The Kaplan-Meier curves from the univariate overall survival analysis are shown in Fig. 4. The correlation of both the clinicopathological parameters and the pathological parameters between the two groups (PTV $\geq 18 \mathrm{~cm}^{3}$; PTV $<18 \mathrm{~cm}^{3}$ ) is shown 
Table I. Association between pathological tumor volume and clinicopathological parameters $(n=47)$.

\begin{tabular}{|c|c|c|c|}
\hline Parameter & Number & $\begin{array}{c}\text { PTV } \\
\left(\text { Mean } \pm \text { standard deviation } \mathrm{cm}^{3}\right)\end{array}$ & P-value \\
\hline Age & & & $0.61^{\mathrm{a}}$ \\
\hline$<64$ & 23 & $9.37 \pm 12.30$ & \\
\hline$\geq 64$ & 24 & $11.20 \pm 11.96$ & \\
\hline Sex & & & $0.57^{b}$ \\
\hline Male & 25 & $12.53 \pm 14.28$ & \\
\hline Female & 22 & $7.77 \pm 8.44$ & \\
\hline Site & & & $0.68^{\mathrm{a}}$ \\
\hline Tongue & 29 & $9.73 \pm 11.34$ & \\
\hline Others & 18 & $11.24 \pm 13.35$ & \\
\hline Pathological T classification & & & $<0.01^{\mathrm{c}}$ \\
\hline $\mathrm{T} 1$ & 5 & $0.71 \pm 0.69$ & \\
\hline $\mathrm{T} 2$ & 22 & $5.33 \pm 3.71$ & \\
\hline T3 & 9 & $16.96 \pm 9.65$ & \\
\hline $\mathrm{T} 4$ & 11 & $19.16 \pm 18.31$ & \\
\hline Pathological N classification & & & $0.58^{c}$ \\
\hline N0 & 14 & $8.35 \pm 10.09$ & \\
\hline N1 & 5 & $5.43 \pm 3.86$ & \\
\hline $\mathrm{N} 2$ & 28 & $12.15 \pm 13.61$ & \\
\hline Pathological stage & & & $<0.02^{\mathrm{c}}$ \\
\hline I & 3 & $0.37 \pm 0.16$ & \\
\hline II & 6 & $4.14 \pm 2.61$ & \\
\hline III & 7 & $8.91 \pm 5.96$ & \\
\hline IV & 31 & $12.77 \pm 13.76$ & \\
\hline Radiation therapy & & & $0.52^{\mathrm{b}}$ \\
\hline Absent & 31 & $7.90 \pm 8.00$ & \\
\hline Present & 16 & $14.97 \pm 16.75$ & \\
\hline Extracapsular extension & & & $0.51^{\mathrm{a}}$ \\
\hline Absent & 33 & $9.50 \pm 11.28$ & \\
\hline Present & 14 & $12.11 \pm 13.92$ & \\
\hline Positive surgical margin & & & $<0.03^{\mathrm{b}}$ \\
\hline Absent & 38 & $7.71 \pm 8.73$ & \\
\hline Present & 9 & $21.27 \pm 17.68$ & \\
\hline Positive surgical margin and/or extracapsular extension & & & $0.38^{\mathrm{b}}$ \\
\hline Absent & 29 & $8.01 \pm 8.97$ & \\
\hline Present & 18 & $14.00 \pm 15.35$ & \\
\hline
\end{tabular}

PTV, pathological tumor volume. ${ }^{\mathrm{a} t-t e s t} .{ }^{\mathrm{b}} \mathrm{Mann}-$ Whitney $\mathrm{U}$ test. ${ }^{\mathrm{c}}$ Kruskal-Wallis test.

in Table II. A PTV of $\geq 18 \mathrm{~cm}^{3}$ was more frequently found in patients with a pathological $\mathrm{T}$ classification of 3-4 $(\mathrm{P}<0.01)$, who had received postoperative radiation $(\mathrm{P}<0.01)$, who showed a positive surgical margin $(\mathrm{P}<0.01)$, and who showed a positive surgical margin and/or extracapsular extension $(\mathrm{P}<0.02)$. A PTV of $\geq 18 \mathrm{~cm}^{3}$ was significantly correlated with larger size $(\mathrm{P}<0.01)$, tumor thickness $(\mathrm{P}<0.01)$, and the depth of invasion $(\mathrm{P}<0.01)$. The patients with a PTV of $\geq 18 \mathrm{~cm}^{3}$ showed significantly shorter local recurrence-free survival than those with a PTV of $<18 \mathrm{~cm}^{3}$ $(\mathrm{P}<0.01)$. However, the patients with PTV of $\geq 18 \mathrm{~cm}^{3} \mathrm{did}$ not show shorter regional recurrence-free survival $(\mathrm{P}=0.58)$, or distant metastasis-free survival $(\mathrm{P}=0.24)$. The Kaplan-Meier curves from the univariate analysis of the local recurrence-free survival are shown in Fig. 5.

The multivariate survival analyses. We performed multivariate analyses of overall survival and local recurrence-free survival with adjustments for the primary site, pathological stage, and positive surgical margin and/or extracapsular extension (Table III). A PTV of $\geq 18 \mathrm{~cm}^{3}$ was significantly associated with shorter overall survival $(\mathrm{P}<0.01)$ and local recurrence-free survival $(\mathrm{P}<0.01)$ in the multivariate analysis. 
A Pathological tumor volume $\left(\mathrm{cm}^{3}\right)$
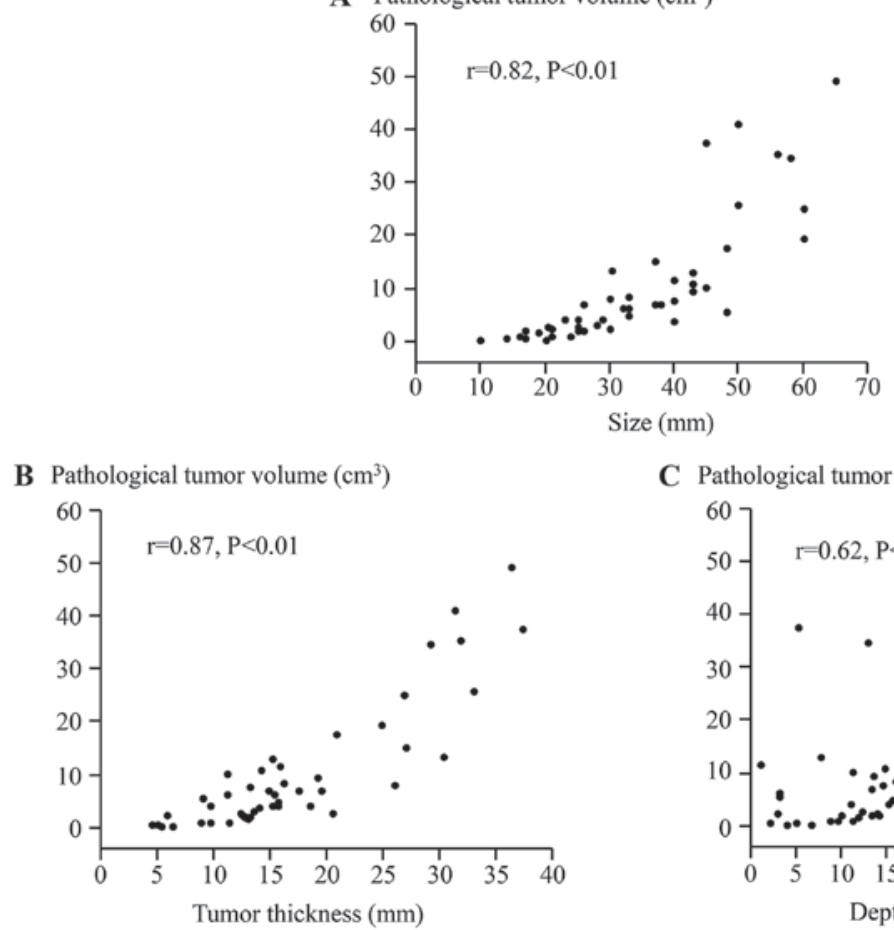

C Pathological tumor volume $\left(\mathrm{cm}^{3}\right)$

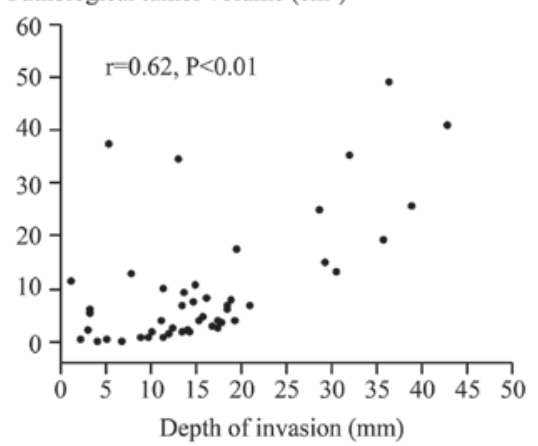

Figure 2. Relationship between (A) the pathological tumor volume and size, (B) the pathological tumor volume and the tumor thickness and (C) the pathological tumor volume and the depth of invasion among 47 patients with oral squamous cell carcinoma in a simple regression analysis.

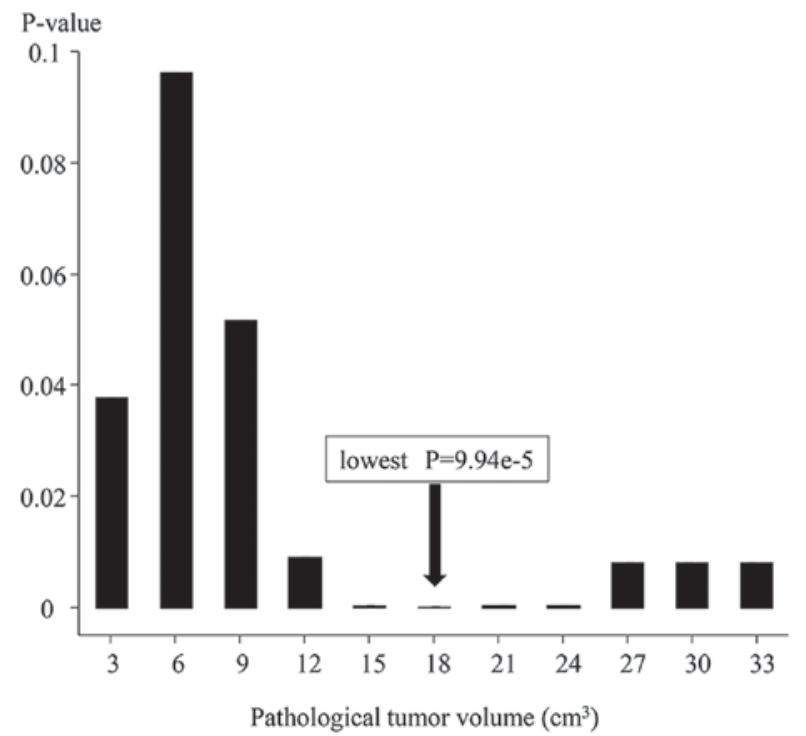

Figure 3. P-values of the univariate Cox proportional hazard model. To determine the factors associated overall survival using different cut-off pathological tumor volume values in 47 patients with oral squamous cell carcinoma, P-values of the univariate Cox proportional hazard model were compared. A pathological tumor volume of $18 \mathrm{~cm}^{3}$ had the lowest P-value ( $9.94 \times 10^{-5}$; arrow).

\section{Discussion}

The results of the using univariate and multivariate analyses in the present study showed-for the first time-that a PTV of $\geq 18 \mathrm{~cm}^{3}$ was significantly associated with shorter overall survival and local recurrence-free survival in patients with oral SCC.

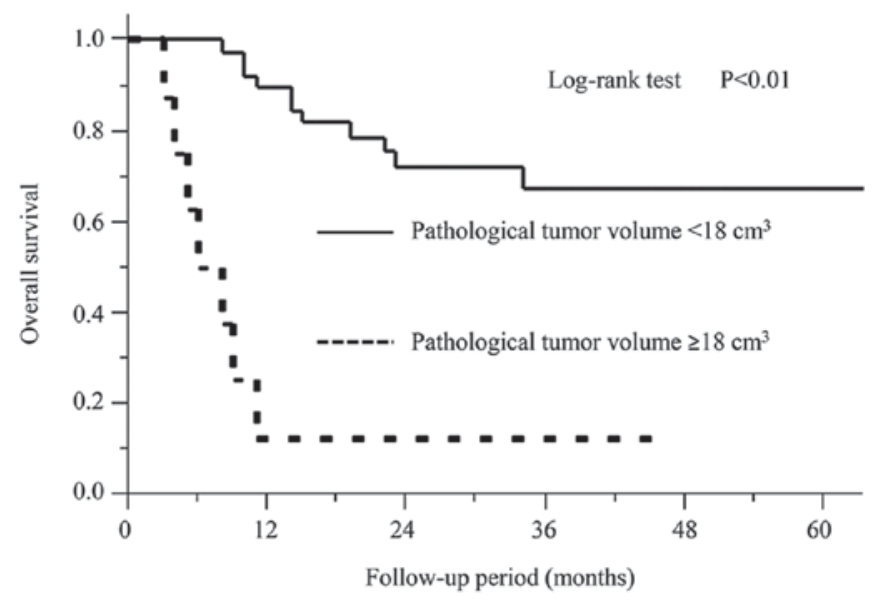

Figure 4. Kaplan-Meier analysis of overall survival. A pathological tumor volume of $\geq 18 \mathrm{~cm}^{3}$ was associated with significantly shorter overall survival $(\mathrm{P}<0.01)$.

Both the depth of invasion and the tumor thickness were considered representative prognostic parameters for oral SCC $(6,7)$. In a review of 55 clinical studies, both the depth of invasion and the tumor thickness were significantly correlated with overall survival in oral SCC (6). Indeed, the significant correlation between overall survival and these pathological parameters (tumor thickness and depth of invasion) that was found in our previous and present studies was in good agreement with previous findings (6,7).

The PTV, which is calculated by three-dimensional measurements, has been reported as a pathological parameter in various sites of cancer (9-13). Mucke et al (9) showed a significant correlation between a larger PTV and shorter 
Table II. Association of clinicopathological parameters and continuative pathological parameters with PTV $\left(<18 \mathrm{~cm}^{3} / \geq 18 \mathrm{~cm}^{3}\right)$.

\begin{tabular}{|c|c|c|c|}
\hline Parameter & PTV $<18 \mathrm{~cm}^{3}(\mathrm{n}=39)$ & PTV $\geq 18 \mathrm{~cm}^{3}(\mathrm{n}=8)$ & P-value \\
\hline Age & & & $0.48^{\mathrm{a}}$ \\
\hline$<64$ & 20 & 3 & \\
\hline$\geq 64$ & 19 & 5 & \\
\hline Sex & & & $0.17^{\mathrm{a}}$ \\
\hline Male & 19 & 6 & \\
\hline Female & 20 & 2 & \\
\hline Site & & & $0.45^{\mathrm{a}}$ \\
\hline Tongue & 25 & 4 & \\
\hline Others & 14 & 4 & \\
\hline Pathological T classification & & & $<0.01^{\mathrm{a}}$ \\
\hline $\mathrm{T} 1-2$ & 27 & 0 & \\
\hline $\mathrm{T} 3-4$ & 12 & 8 & \\
\hline Pathological N classification & & & $0.24^{\mathrm{a}}$ \\
\hline No & 13 & 1 & \\
\hline N1-2 & 26 & 7 & \\
\hline Pathological stage & & & $0.13^{\mathrm{a}}$ \\
\hline I-II & 9 & 0 & \\
\hline III-IV & 30 & 8 & \\
\hline Radiation therapy & & & $<0.01^{\mathrm{a}}$ \\
\hline Absent & 29 & 2 & \\
\hline Present & 10 & 6 & \\
\hline Extracapsular extension & & & $0.17^{\mathrm{a}}$ \\
\hline Absent & 29 & 4 & \\
\hline Present & 10 & 4 & \\
\hline Positive surgical margin & & & $<0.01^{\mathrm{a}}$ \\
\hline Absent & 35 & 3 & \\
\hline Present & 4 & 5 & \\
\hline Positive surgical margin and/or extracapsular extension & & & $<0.02^{\mathrm{a}}$ \\
\hline Absent & 27 & 2 & \\
\hline Present & 12 & 6 & \\
\hline Size (mm) & & & $<0.01^{\mathrm{b}}$ \\
\hline Mean \pm standard deviation & $29.56 \pm 9.97$ & $55.50 \pm 6.63$ & \\
\hline Tumor thickness (mm) & & & $<0.01^{\mathrm{b}}$ \\
\hline Mean \pm standard deviation & $14.15 \pm 5.77$ & $31.32 \pm 4.32$ & \\
\hline Depth of invasion (mm) & & & $<0.01^{\mathrm{b}}$ \\
\hline Mean \pm standard deviation & $13.07 \pm 6.70$ & $28.95 \pm 13.16$ & \\
\hline
\end{tabular}

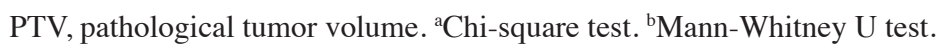

overall survival in 437 patients with tongue SCC. We have also reported on the PTV in hypopharyngeal SCC (10). We hypothesized that a larger PTV would be related to shorter overall survival in patients with SCC of the entire oral cavity. The significant correlation between the PTV and overall survival in the present study supported this hypothesis.

In a previous study about the PTV in tongue SCC (9), the rate of local recurrence-free survival was not estimated. For the first time, we demonstrated that a PTV of $\geq 18 \mathrm{~cm}^{3}$ is significantly associated with shorter local recurrence-free survival. The result suggests that postoperative therapy, such as chemoradiotherapy has the potential to improve local recurrence-free survival in patients with a PTV of $\geq 18 \mathrm{~cm}^{3}$. Furthermore, we demonstrated-for the first time-that the PTV in oral SCC is significantly correlated with the pathological parameters (size, tumor thickness, and depth of invasion).

The extracapsular extension is considered a significant prognostic factor in head and neck cancer, including oral cancer (8). In the present study, the PTV was not correlated with the extracapsular extension in Tables I and II, and 
Table III. Multivariate analysis of overall survival and local recurrence-free survival.

\begin{tabular}{|c|c|c|c|c|c|c|}
\hline \multirow[b]{2}{*}{ Parameter } & \multicolumn{3}{|c|}{ Overall survival } & \multicolumn{3}{|c|}{ Local recurrence-free survival } \\
\hline & HR & $95 \% \mathrm{CI}$ & P-value & HR & $95 \% \mathrm{CI}$ & P-value \\
\hline Primary site & & & 0.07 & & & 0.35 \\
\hline Tongue & 1 & & & 1 & & \\
\hline Others & 0.38 & $0.12-1.08$ & & 1.87 & $0.50-7.83$ & \\
\hline Pathological stage & & & 0.12 & & & 0.94 \\
\hline I-II & 1 & & & 1 & & \\
\hline III-IV & 3.98 & $0.73-74.07$ & & 1.09 & $0.15-22.03$ & \\
\hline $\begin{array}{l}\text { Positive surgical margin and/or } \\
\text { extracapsular extension }\end{array}$ & & & 0.44 & & & 0.59 \\
\hline Absent & 1 & & & 1 & & \\
\hline Present & 1.57 & $0.49-4.92$ & & 0.66 & $0.14-3.03$ & \\
\hline PTV & & & $<0.01$ & & & $<0.01$ \\
\hline$<18 \mathrm{~cm}^{3}$ & 1 & & & 1 & & \\
\hline$\geq 18 \mathrm{~cm}^{3}$ & 8.30 & $2.46-29.45$ & & 8.54 & $1.81-44.72$ & \\
\hline
\end{tabular}

PTV, pathological tumor volume; HR, hazard ratio; CI, confidence interval.

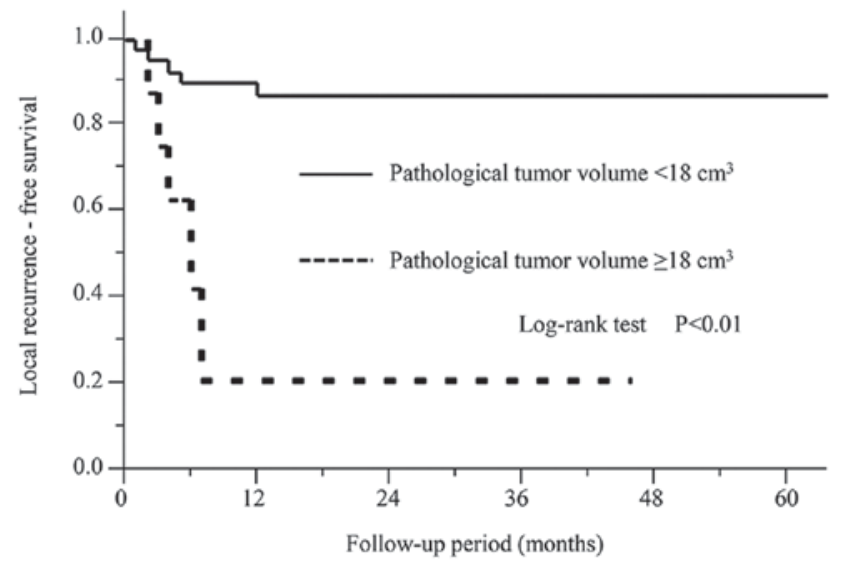

Figure 5. Kaplan-Meier analysis of local recurrence-free survival. A pathological tumor volume of $\geq 18 \mathrm{~cm}^{3}$ was associated with a significantly shorter local recurrence-free survival $(\mathrm{P}<0.01)$.

the patients with a PTV of $\geq 18 \mathrm{~cm}^{3}$ did not show a shorter regional recurrence-free survival than those with a PTV of $<18 \mathrm{~cm}^{3}(\mathrm{P}=0.58)$. We believe that this fundamental difference in the prognostic utility of PTV and extracapsular extension may have been because PTV was a prognostic factor obtained from the primary tumor, while extracapsular extension was a prognostic factor obtained from the cervical lymph node.

We showed the results of multivariate analyses which were adjusted by the Cox proportional hazards model in the present study. We considered PTV not to be an independent prognostic factor, although it was a prognostic factor in multivariate analyses after adjustments were made for the primary site, pathological stage, and positive surgical margin and/or extracapsular extension. To exclude the influence of the confounding factors, we underwent the multivariate analyses in the present study. Since PTV was significantly associated with pathological $\mathrm{T}$ classification, pathological stage, positive surgical margin, size, tumor thickness, and depth of invasion in the present study, we considered that PTV is not an independent prognostic factor.

The present study is associated with some limitations, including the relatively small study population and its retrospective nature. A future prospective analysis of a larger study population will yield more accurate results and will hopefully provide insight into the potential application of the PTV as a prognostic tool.

In conclusion, we demonstrated, for the first time, that a PTV of $\geq 18 \mathrm{~cm}^{3}$ was significantly correlated with shorter overall survival and local recurrence-free survival in patients with SCC of the entire oral cavity. Thus, these results suggest that the PTV is a prognostic parameter in oral SCC.

\section{Acknowledgements}

Not applicable.

\section{Funding}

This study was supported by JSPS KAKENHI (grant no. $16 \mathrm{~K} 11253$ ).

\section{Availability of data and materials}

The datasets used and/or analyzed during the current study are available from the corresponding author on reasonable request.

\section{Authors' contributions}

NM contributed to the data analysis and drafting of the manuscript. HS acquired the data, contributed to the study design 
and revised the manuscript critically for intellectual content. $\mathrm{NH}$ and $\mathrm{YH}$ also acquired the data and revised the manuscript critically for intellectual content. MS contributed to the study design and revised the manuscript critically for intellectual content. All authors approved the final version of the manuscript.

\section{Ethics approval and consent to participate}

Ethics approval was obtained from the institutional review board of Aichi Cancer Center Hospital. All patients provided their informed consent for all of the examinations and treatments.

\section{Consent for publication}

All patients provided their informed consent.

\section{Competing interests}

The authors declare that they have no competing interests.

\section{References}

1. Ko B, Parvathaneni U, Hudgins PA and Anzai Y: Do radiologists report the TNM staging in radiology reports for head and neck cancers? A national survey study. AJNR Am J Neuroradiol 37: 1504-1509, 2016.

2. Joo YH, Hwang SH, Sun DI, Cho KJ, Park JO and Kim MS: Relationships between tumor volume and lymphatic metastasis and prognosis in early oral tongue cancer. Clin Exp Otorhinolaryngol 6: 243-248, 2013.

3. Schwartz DL, Rajendran J, Yueh B, Coltrera MD, Leblanc M, Eary J and Krohn K: FDG-PET prediction of head and neck squamous cell cancer outcomes. Arch Otolaryngol Head Neck Surg 130: 1361-1367, 2004.

4. $\mathrm{Hu} \mathrm{H}$, Cheng KL, Xu XQ, Wu FY, Tyan YS, Tsai CH and Shen CY: Predicting the prognosis of oral tongue carcinoma using a simple quantitative measurement based on preoperative MR imaging: Tumor thickness versus tumor volume. AJNR Am J Neuroradiol 36: 1338-1342, 2015.

5. Benhamou Y, Picco V and Pages G: The telomere proteins in tumorigenesis and clinical outcomes of oral squamous cell carcinoma. Oral Oncol 57: 46-53, 2016.

6. Pentenero M, Gandolfo S and Carrozzo M: Importance of tumor thickness and depth of invasion in nodal involvement and prognosis of oral squamous cell carcinoma: A review of the literature. Head Neck 27: 1080-1091, 2005.
7. Suzuki H, Fukuyama R, Hasegawa Y, Tamaki T, Nishio M, Nakashima T and Tatematsu M: Tumor thickness, depth of invasion and Bcl-2 expression are correlated with FDG-uptake in oral squamous cell carcinomas. Oral Oncol 45: 891-897, 2009.

8. Fan S, Tang QL, Lin YJ, Chen WL, Li JS, Huang ZQ, Yang ZH, Wang YY, Zhang DM, Wang HJ, et al: A review of clinical and histological parameters associated with contralateral neck metastases in oral squamous cell carcinoma. Int J Oral Sci 3: 180-191, 2011.

9. Mucke T, Mitchell DA, Ritschl LM, Tannapfel A, Wolff KD, Kesting MR, Loeffelbein DJ and Kanatas A: Influence of tumor volume on survival in patients with oral squamous cell carcinoma. J Cancer Res Clin Oncol 141: 1007-1011, 2015.

10. Suzuki H, Nishio M, Nakanishi H, Hanai N, Hirakawa H, Kodaira T, Tamaki T and Hasegawa Y: Impact of total lesion glycolysis measured by $18 \mathrm{~F}-\mathrm{FDG}-\mathrm{PET} / \mathrm{CT}$ on overall survival and distant metastasis in hypopharyngeal cancer. Oncol Lett 12: 1493-1500, 2016.

11. Murphy JD, Chisholm KM, Daly ME, Wiegner EA, Truong D, Iagaru A, Maxim PG, Loo BW Jr, Graves EE, Kaplan MJ, et al: Correlation between metabolic tumor volume and pathologic tumor volume in squamous cell carcinoma of the oral cavity. Radiother Oncol 101: 356-361, 2011.

12. Knoedler JJ, Karnes RJ, Thompson RH, Rangel LJ, Bergstralh EJ and Boorjian SA: The association of tumor volume with mortality following radical prostatectomy. Prostate Cancer Prostatic Dis 17: 144-148, 2014.

13. Sridhar P, Mercier G, Tan J, Truong MT, Daly B and Subramaniam RM: FDG PET metabolic tumor volume segmentation and pathologic volume of primary human solid tumors. AJR Am J Roentgenol 202: 1114-1119, 2014.

14. Sobin LH, Gospodarowicz MK and Wittekind C: International Union against Cancer. TNM classification of malignant tumours. 7th edition. Wiley-Blackwell (UK), pp22-62, 2010.

15. Suzuki H, Hanai N, Nishikawa D, Fukuda Y, Koide Y, Kodaira T, Tachibana H, Tomita N, Makita C and Hasegawa Y: The Charlson comorbidity index is a prognostic factor in sinonasal tract squamous cell carcinoma. Jpn J Clin Oncol 46: 646-651, 2016.

16. Strongin A, Yovino S, Taylor R, Wolf J, Cullen K, Zimrin A, Strome S, Regine W and Suntharalingam M: Primary tumor volume is an important predictor of clinical outcomes among patients with locally advanced squamous cell cancer of the head and neck treated with definitive chemoradiotherapy. Int J Radiat Oncol Biol Phys 82: 1823-1830, 2012.

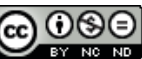

$$
\begin{aligned}
& \text { This work is licensed under a Creative Commons } \\
& \text { Attribution-NonCommercial-NoDerivatives } 4.0 \\
& \text { International (CC BY-NC-ND 4.0) License. }
\end{aligned}
$$

